\title{
Gestational age, mode of birth and breastmilk feeding all influence acute early childhood gastroenteritis: a record-linkage cohort study
}

Jason P. Bentley ${ }^{1,4^{*}}$, Judy M. Simpson², Jenny R. Bowen ${ }^{1,3}$, Jonathan M. Morris ${ }^{1}$, Christine L. Roberts ${ }^{1}$ and Natasha Nassar ${ }^{1}$

\begin{abstract}
Background: Acute gastroenteritis (AGE) is a leading cause of infectious morbidity in childhood. Clinical studies have implicated caesarean section, early birth and formula feeding in modifying normal gut microbiota development and immune system homeostasis in early life. Rates of early birth and cesarean delivery are also increasing worldwide. This study aimed to investigate the independent and combined associations of the mode and timing of birth and breastmilk feeding with AGE hospitalisations in early childhood.

Methods: Population-based record-linkage study of 893,360 singleton livebirths of at least 33 weeks gestation without major congenital conditions born in hospital, New South Wales, Australia, 2001-2011. Using age at first AGE hospital admission, Cox-regression was used to estimate the associations for gestational age, vaginal birth or caesarean delivery by labour onset and formula-only feeding while adjusting for confounders.

Results: There were 41,274 (4.6\%) children admitted to hospital at least once for AGE and the median age at first admission was 1.4 years. Risk of AGE admission increased with decreasing gestational age (37-38 weeks: $15 \%$ increased risk, 33-36 weeks: $25 \%$ ), caesarean section (20\%), planned birth (17\%) and formula-only feeding (18\%). The rate of AGE admission was highest for children who were born preterm by modes of birth other than vaginal birth following the spontaneous onset of labour and who received formula-only at discharge from birth care (62-78 \%).

Conclusions: Vaginal birth following spontaneous onset of labour at 39+ weeks gestation with any breastfeeding minimised the risk of gastroenteritis hospitalisation in early childhood. Given increasing trends in early planned birth and caesarean section worldwide, these results provide important information about the impact obstetric interventions may have on the development of the infant gut microbiota and immunity.
\end{abstract}

Keywords: Acute gastroenteritis, Early term birth, Caesarean section, Child, Healthy start to life, Breastfeeding

\section{Background}

Acute gastroenteritis is characterised by viral or bacterial infection causing diarrhea and vomiting and is a leading cause of infectious morbidity in infants and children worldwide even in developed countries including Australia, where the incidence is highest in the first two years of life

\footnotetext{
* Correspondence: jben9630@uni.sydney.edu.au

${ }^{1}$ Clinical and Population Perinatal Health Research, Kolling Institute, University of Sydney, Sydney, NSW, Australia

${ }^{4}$ University Department of Obstetrics, Building 52, Royal North Shore Hospital, St Leonards, NSW 2065, Australia

Full list of author information is available at the end of the article
}

[1, 2]. Many factors in early childhood are associated with an increased susceptibility to gastroenteritis, such as poor social conditions, diet and antibiotic use [3, 4]. Additionally, gut microbial composition and immunological immaturity in the newborn may also play an important role [5-8].

Bacterial exposures from the birth canal and perianal region during vaginal birth are important precursors for the colonisation of the gut in the first few days of life. To prepare for this, cells of the adaptive immune system are recruited to the fetal intestinal tissue with a 
transition to adult T-cells occurring in the third trimester [5]. Once born, a multitude of pathways activate to prepare the immune system and intestinal epithelial cells to manage the high density of bacteria in the gut, establishing a homeostasis between the immune system and gut microbiota [6]. The later the gestational age at birth, the better prepared the newborns immune system is for establishing homeostasis. Bacterial colonisation and the immune response in the gut are further supported by exposure to the nutritional, growth and immunological factors contained in breastmilk [7]. Clinical studies have shown gut colonisation is typically imbalanced towards bacterial species such as E. Coli. in infants delivered by caesarean section or fed formula rather than breastmilk [8].

This suggests potential common biological mechanisms by which shortened gestation, delivery by caesarean section and a lack of breastmilk exposure may increase susceptibility to gut infections by disturbing or modifying gut microbiota and immune system homeostasis in early life. Previous population-based studies have investigated the independent associations of vaginal birth and breastmilk feeding with childhood gastroenteritis [9-11]. Few have examined the association with gestational age, especially those born around term, either preterm or early term (37-38 weeks gestation) and there is evidence these infants and children are at an increased risk of morbidity generally [12]. The combined risk of gastroenteritis associated with these birth characteristics is currently unknown, but such information is important given worldwide increasing rates of early planned birth and delivery by caesarean section [13-16], which are also associated with reduced rates of breastmilk feeding [17, 18]. Record linkage of large routinely collected population-based data with standardised clinical information provides a powerful approach to investigate the combined risk of gastroenteritis for multiple birth characteristics.

The aim of this study was to investigate the independent and combined associations of the mode and timing of birth and breastmilk feeding with gastroenteritis hospitalisations in early childhood.

\section{Methods}

\section{Study population}

The study population included all singleton live births of $\geq 33$ weeks gestation from 2001 to 2011 in New South Wales (NSW), Australia. Stillbirths and births to nonNSW resident mothers were excluded as these births have no opportunity for follow-up through record linkage with hospital admissions in NSW. Infants with major congenital conditions, born before 33 weeks gestation, or twins and higher-order births were excluded as they have different risk profiles, outcomes and models of care [19]. Each child in the study population was followed from birth until the age of 6 years, death or the end of the study period (30 June 2012), whichever occurred first.

This study used linked birth, hospital and death records from the NSW Perinatal Data Collection (PDC), NSW Admitted Patient Data Collection (APDC) and Registry of Births, Deaths and Marriages Death Registrations (fact of death) respectively. The PDC is a population-based statutory collection covering all live births and stillbirths of at least 20 weeks gestation or, if gestational age is unknown, at least 400 grams birthweight. It contains information on maternal characteristics, pregnancy, labour and delivery factors, and infant outcomes. The APDC includes demographic and hospitalisation related data for every inpatient admitted to any public or private hospital in NSW. Diagnoses for each admission are coded according to the $10^{\text {th }}$ revision of the International Classification of Disease, Australian Modification (ICD-10-AM) [20]. Probabilistic record linkage of these data was performed by the NSW Centre for Health Record Linkage using methods described previously and only de-identified information was provided to the researchers [21]. The data sources used for this study require ethical and data custodian approval to access, link (by an independent and approved authority) and release for research. Approval for the record linkage and use of the data for research was obtained from the NSW Population and Health Services Research Ethics Committee and the appropriate data custodians.

\section{Mode of birth, timing of birth and infant feeding at discharge}

The study factors of interest were mode of birth, gestational age (timing of birth) and infant feeding status at discharge from birth care. Mode of birth was defined using the combination of labour onset and type of birth (vaginal birth or caesarean section) and categorised as vaginal birth following spontaneous onset of labour, caesarean section following spontaneous onset of labour, vaginal birth following labour induction, caesarean section following labour induction, or pre-labour caesarean section. Gestational age is reported in completed weeks of gestation, as determined by the best clinical estimate including early ultrasound and last menstrual period. This was categorised as preterm (33-36 weeks), early-term (37-38 weeks) or term (39-42 weeks) birth. Infant feeding status at discharge from birth care is recorded using one or more of the following three categories: "breastfeeding", "expressed breastmilk" or "infant formula". These categories were used to create two independent groups: any breastmilk feeding (breastfeeding or expressed breastmilk feeding without infant formula) and formula-only feeding (infant formula without breastfeeding or expressed breastmilk feeding). 


\section{Study outcome}

The study outcome was hospital admissions for gastroenteritis, which we refer to as acute gastroenteritis (AGE). Primary or additional diagnoses for gastroenteritis (ICD-10-AM: A00-A09 or K52) were used to identify admissions. Inter-hospital transfers were treated as a continuation of an admission and not a new admission. AGE admissions within 7 days of a previous AGE admission were also treated as a single event.

\section{Statistical analysis}

The proportion and number of children with none, one, or more than one AGE admission in the study period by maternal and perinatal characteristics were calculated. Cox proportional hazards regression was used to estimate the adjusted Hazard Ratios and $95 \%$ confidence intervals for the independent and combined associations between the study exposures and first AGE hospitalisation with child age as the timescale and age at discharge from birth care as entry into observation. For censored individuals, age was recorded as the earliest of death, sixth birthday, or end of the study period (30 June 2012).

The covariates used in the study reflect known risk factors identified in the literature $[4,9,12,22]$. Covariates included were: parity (primiparae or multiparae), maternal age $(<20,20-24,25-29,30-34,35-39,40+$ years $)$, country of birth (Australia-born or other), socio-economic status quintile (Australian Bureau of Statistics Socio-Economic Index For Areas - Index of Relative Socio-economic Advantage) [23], smoking during pregnancy, hypertensive disorders of pregnancy (gestational hypertension, preeclampsia or eclampsia), diabetes mellitus in pregnancy (gestational or pre-existing) [24, 25], baby's sex, 5-minute Apgar score $<7$, birthweight (standardised by gestational age and sex) [26], presence of AGE or other infection specific to the perinatal period (ICD-10-AM: P35-P39), admission to a Special Care Nursery (SCN) or Neonatal Intensive Care Unit (NICU) and infant birth admission length of stay (standardised by gestational age and type of birth using the study population). To account for the inclusion of rotavirus vaccination in the national immunisation program from 1 July 2007, year of birth was categorised as before July 2007 or July 2007 onwards. All covariates were adjusted for in the analysis except for admission to SCN or NICU and 5-minute Apgar score $<7$ which were omitted from the model due to high colinearity with birth at 33-36 weeks gestation. The assumption of proportional hazards was assessed using standard diagnostics and found to be reasonable.

Cox-regression was used to estimate the associations for the study exposures under variations of the study population and design, to assess the robustness of the main findings and for comparability with other studies of associations between birth factors and childhood hospitalisations. The variations investigated were: a subpopulation of low risk liveborn singleton pregnancies (infants born at $\geq 37$ weeks gestation, cephalic presenting, and a birthweight between the $10^{\text {th }}$ and $90^{\text {th }}$ percentiles for gestational age and sex, to women aged 20-34 years without medical conditions), using children with no hospital admissions only as the controls, using only a primary diagnosis of gastroenteritis, restricting to AGE hospitalisations within the first year of life or within the first two years of life (rather than six), and restricting to births from July 2007 onwards (universal rotavirus vaccination).

The level of missing information was minimal for all variables $(<0.01$ to $0.10 \%)$, with the exception of infant feeding at discharge. Collection of infant feeding status began in mid-2006 and was only available for $51.8 \%$ of births, within which $0.95 \%$ were missing. As the per cent missing across all variables except infant feeding affected only $0.23 \%$ of records, these were excluded. However, as infant feeding was an exposure of interest, it was imputed using a logistic model following recommendations in the literature (see Additional file 1). All analyses were performed using Stata 13.0 (StataCorp LP, TX, USA).

\section{Results}

Of the 893,360 children included in the study, $28 \%$ were delivered by caesarean section, $41 \%$ were planned births (pre-labour caesarean or following labour induction), $27 \%$ were born before 39 weeks gestation and $12 \%$ were fed only formula in the birth admission (Table 1). There were 38,085 (4.3\%) children admitted to hospital for AGE once and 3,189 (0.4\%) more than once (7.7 \% recurrence rate). The proportion of children admitted for AGE was higher for those delivered by caesarean section, born before 39 weeks gestation and fed only formula. Average followup per child was 4.37 years (standard deviation: 1.88), with a total follow-up time of 3,907,163 years. For the 41,274 children admitted, the median age at first AGE hospital admission was 1.43 years (Inter-quartile range 0.77 to 2.48 years).

Compared to vaginal birth following spontaneous onset of labour, all other modes of birth were independently associated with a 12-23\% increased rate of AGE admission (Table 2). In general those modes of birth including delivery by caesarean section were similar with largely overlapping confidence intervals $(19-23 \%$ increased rate of admission), while vaginal birth following labour induction was intermediary to these modes of birth and vaginal birth following spontaneous onset of labour (12\% increased rate of admission). Adjusted associations for all variables are presented in the Additional file 2. The rate of AGE admission increased with decreasing gestational age. Birth at 37-38 weeks 
Table 1 Maternal and perinatal characteristics for children admitted to hospital once and more than once for acute gastroenteritis, NSW 2001-2011

\begin{tabular}{|c|c|c|c|c|c|c|c|c|}
\hline \multirow[t]{3}{*}{ Variable } & \multicolumn{6}{|c|}{ Number of AGE hospital admissions } & \multirow{2}{*}{\multicolumn{2}{|c|}{ Total $(N=893,360)$}} \\
\hline & \multicolumn{2}{|c|}{ None $(N=852,086)$} & \multicolumn{2}{|c|}{ One $(N=38,085)$} & \multicolumn{2}{|c|}{ Two or more $(N=3189)$} & & \\
\hline & $\bar{N}$ & Row $\%^{\mathrm{a}}$ & $\bar{N}$ & Row \% ${ }^{\mathrm{a}}$ & $\bar{N}$ & Row $\%^{a}$ & $\overline{\mathrm{N}}$ & Col. $\%^{b}$ \\
\hline \multicolumn{9}{|l|}{ Mode of birth } \\
\hline Vaginal birth - spontaneous onset of labour & 445,535 & 95.6 & 18,929 & 4.1 & 1469 & 0.3 & 465,933 & 52.2 \\
\hline Vaginal birth - labour induction & 173,429 & 95.1 & 8220 & 4.5 & 722 & 0.4 & 182,371 & 20.4 \\
\hline Caesarean section - pre-labour & 132,892 & 95.3 & 6017 & 4.3 & 561 & 0.4 & 139,470 & 15.6 \\
\hline Caesarean section - spontaneous onset of labour & 57,537 & 94.9 & 2820 & 4.7 & 252 & 0.4 & 60,609 & 6.8 \\
\hline Caesarean section - labour induction & 42,693 & 94.9 & 2099 & 4.7 & 185 & 0.4 & 44,977 & 5.0 \\
\hline \multicolumn{9}{|l|}{ Gestational age (weeks) } \\
\hline $33-36$ & 36,508 & 94.4 & 1952 & 5.0 & 225 & 0.6 & 38,685 & 4.3 \\
\hline $37-38$ & 188,164 & 95.0 & 8985 & 4.5 & 834 & 0.4 & 197,983 & 22.2 \\
\hline $39-42$ & 627,414 & 95.5 & 27,148 & 4.1 & 2130 & 0.3 & 656,692 & 73.5 \\
\hline \multicolumn{9}{|l|}{ Maternal age (years) } \\
\hline$<20$ & 31,020 & 92.8 & 2154 & 6.4 & 247 & 0.7 & 33,421 & 3.7 \\
\hline $20-24$ & 118,300 & 94.0 & 6902 & 5.5 & 676 & 0.5 & 125,878 & 14.1 \\
\hline $25-29$ & 235,736 & 95.1 & 11,235 & 4.5 & 926 & 0.4 & 247,897 & 27.8 \\
\hline $30-34$ & 282,186 & 95.8 & 11,464 & 3.9 & 853 & 0.3 & 294,503 & 33.0 \\
\hline $35-39$ & 153,271 & 96.4 & 5266 & 3.3 & 406 & 0.3 & 158,943 & 17.8 \\
\hline $40+$ & 31,573 & 96.5 & 1064 & 3.3 & 81 & 0.2 & 32,718 & 3.7 \\
\hline Primiparae & 353,744 & 95.0 & 17,306 & 4.6 & 1468 & 0.4 & 372,518 & 41.7 \\
\hline Australian Born & 598,374 & 95.0 & 29,024 & 4.6 & 2566 & 0.4 & 629,964 & 70.5 \\
\hline \multicolumn{9}{|l|}{ Socio-economic advantage } \\
\hline 1st Quintile (Highest) & 173,516 & 96.1 & 6605 & 3.7 & 457 & 0.3 & 180,578 & 20.2 \\
\hline 2nd Quintile & 162,516 & 95.9 & 6420 & 3.8 & 501 & 0.3 & 169,437 & 19.0 \\
\hline 3rd Quintile & 178,752 & 95.5 & 7823 & 4.2 & 604 & 0.3 & 187,179 & 21.0 \\
\hline 4th Quintile & 175,417 & 94.9 & 8557 & 4.6 & 775 & 0.4 & 184,749 & 20.7 \\
\hline 5th Quintile (Lowest) & 161,885 & 94.4 & 8680 & 5.1 & 852 & 0.5 & 171,417 & 19.2 \\
\hline Smoking during pregnancy & 126,685 & 94.2 & 7101 & 5.3 & 686 & 0.5 & 134,472 & 15.1 \\
\hline Diabetes & 53,822 & 95.3 & 2420 & 4.3 & 220 & 0.4 & 56,462 & 6.3 \\
\hline Hypertension & 74,126 & 94.5 & 3956 & 5.0 & 364 & 0.5 & 78,446 & 8.8 \\
\hline Baby's sex - Male & 436,304 & 95.2 & 20,085 & 4.4 & 1724 & 0.4 & 458,113 & 51.3 \\
\hline \multicolumn{9}{|l|}{ Year of birth } \\
\hline Prior to 1 July 2007 & 473,607 & 93.6 & 29,552 & 5.8 & 2662 & 0.5 & 505,821 & 56.6 \\
\hline From 1 July 2007 & 378,479 & 97.7 & 8533 & 2.2 & 527 & 0.1 & 387,539 & 43.4 \\
\hline \multicolumn{9}{|l|}{ Birthweight z-score } \\
\hline$<-2$ & 16,064 & 94.1 & 897 & 5.3 & 117 & 0.7 & 17,078 & 1.9 \\
\hline$[-2,-1)$ & 113,474 & 94.9 & 5570 & 4.7 & 482 & 0.4 & 119,526 & 13.4 \\
\hline$[-1,0)$ & 305,914 & 95.3 & 13,855 & 4.3 & 1154 & 0.4 & 320,923 & 35.9 \\
\hline$[0,1)$ & 281,683 & 95.5 & 12,173 & 4.1 & 994 & 0.3 & 294,850 & 33.0 \\
\hline$[1,2)$ & 108,087 & 95.7 & 4467 & 4.0 & 374 & 0.3 & 112,928 & 12.6 \\
\hline$\geq 2$ & 26,864 & 95.8 & 1123 & 4.0 & 68 & 0.2 & 28,055 & 3.1 \\
\hline
\end{tabular}


Table 1 Maternal and perinatal characteristics for children admitted to hospital once and more than once for acute gastroenteritis, NSW 2001-2011 (Continued)

\begin{tabular}{|c|c|c|c|c|c|c|c|c|}
\hline Admission to SCN/NICU & 111,483 & 94.2 & 6205 & 5.2 & 663 & 0.6 & 118,351 & 13.3 \\
\hline 5 Minute Apgar Score $<7$ & 10,947 & 94.5 & 584 & 5.0 & 59 & 0.5 & 11,590 & 1.3 \\
\hline Infection in birth admission ${ }^{c}$ & 17,475 & 94.1 & 991 & 5.3 & 109 & 0.6 & 18,575 & 2.1 \\
\hline \multicolumn{9}{|c|}{ Birth admission length of stay z-score } \\
\hline$<-1$ & 81,018 & 96.3 & 2893 & 3.4 & 204 & 0.2 & 84,115 & 9.4 \\
\hline$[-1,0)$ & 346,181 & 95.7 & 14,527 & 4.0 & 1171 & 0.3 & 361,879 & 40.5 \\
\hline$[0,1)$ & 351,360 & 95.2 & 16,317 & 4.4 & 1371 & 0.4 & 369,048 & 41.3 \\
\hline$\geq 1$ & 73,527 & 93.9 & 4348 & 5.6 & 443 & 0.6 & 78,318 & 8.8 \\
\hline \multicolumn{9}{|l|}{ Formula-only feeding* } \\
\hline Yes & 52,360 & 96.4 & 1840 & 3.4 & 127 & 0.2 & 54,327 & 11.9 \\
\hline No & 393,156 & 97.4 & 9936 & 2.5 & 660 & 0.2 & 403,752 & 88.1 \\
\hline
\end{tabular}

*Complete cases only $(n=458,079)$, SCN Special Care Nursery, NICU Neonatal Intensive Care Unit, Col. Column

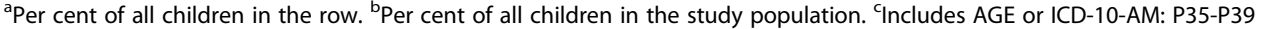

was associated with a $15 \%$ increase in the rate of $\mathrm{AGE}$ admission (adjusted hazard ratio $[\mathrm{aHR}], 1.15 ; 95 \%$ Confidence Interval [CI], 1.12-1.17), and for births at 33-36 weeks gestation was $23 \%$ (aHR, 1.23; $95 \% \mathrm{CI}$, 1.18-1.29). Infants fed only formula (aHR, 1.18; $95 \% \mathrm{CI}$, 1.11-1.24) were also more likely to be admitted for AGE.

Results for the combined associations are presented in Fig. 1. Compared with vaginal birth following spontaneous onset of labour at 39+ weeks gestation with any breastmilk feeding at discharge, early term births with formula-only feeding had an increased rate of AGE of $35 \%$ and preterm birth a $45 \%$ increased rate. Children born at early term with formula-only feeding had a higher rate of admission compared to preterm births that had some breastmilk feeding (35\% versus $23 \%$ ). For the other modes of birth with formula-only feeding, early term births had increased admission rates of 51-66\%, and preterm births had the highest rates ranging from $62-78 \%$. Within births $39+$ weeks gestation, all modes of birth with formula-only feeding compared with vaginal birth following spontaneous onset of labour, had increased rates of admission by $31-45 \%$.

The results were mostly robust to changes in study population or design. Restriction to the first two years of life, low risk pregnancies, the period of rotavirus vaccination or a primary diagnosis of AGE provided generally similar adjusted hazard ratios to those for the selected study population (Table 2). The impact of formula-only feeding was stronger (34\% versus $18 \%$ ) when restricting to the first year of life. Restricting the control group to children with no hospital admissions provided a stronger association for gestational age (33-36 weeks, $44 \%$ versus $23 \%$; 37-38 weeks, $21 \%$ versus $15 \%)$. For the adjusted final models and combined associations for the investigated changes in study population or design see Additional files 2 and 3 .

\section{Discussion}

This is the first population-based study to specifically investigate the combined effects of mode and timing of birth and breastmilk feeding at discharge from birth care on early childhood gastroenteritis hospital admissions. The results show an increased rate of admission in early childhood for being born before 39 weeks gestation, by modes of birth other than vaginal birth following spontaneous onset of labour and formula-only feeding at discharge from birth care. The combined effects highlight the benefit of normal birth and early breastmilk exposure, and are also suggestive of their impact on subsequent gastrointestinal health by possibly modifying or disturbing gut microbiota and immune system homeostasis. These findings are also pertinent in the context of increasing rates of caesarean section and early planned birth.

To our knowledge this is the first study to identify that children born preterm and early term, compared with children born at full term (39+ weeks gestation), had a 38-52 \% and 28-41\% increased rate of AGE admission respectively, regardless of the mode of birth. Previous studies have demonstrated an increased rate of overall pediatric or respiratory hospitalisations for preterm and early term births [12, 27-29]. We also found for preterm and early term births, those with modes of birth other than vaginal birth following spontaneous onset of labour and formula-only feeding at discharge had even higher rates of AGE admission, 51-66 \% and 62-78 \% respectively. Interestingly, children born at early term had higher AGE admission rates than those born preterm who received any breastmilk feeding in the birth admission. Nevertheless, the most vulnerable group of children identified were those born preterm by modes of birth other than vaginal birth following the spontaneous onset of labour and who received formula-only at discharge from birth care. 
Table 2 Associations for age at first hospital admission for acute gastroenteritis by mode of birth, timing of birth and infant formula only at birth for the overall study and selected sub-populations, NSW 2001-2011 a

\begin{tabular}{|c|c|c|c|c|c|c|c|}
\hline & Study Population & Low-risk $^{c}$ & Healthy controls $^{d}$ & From 1 July $2007^{\mathrm{e}}$ & Primary $^{f}$ & 1 -year $^{9}$ & 2-year ${ }^{h}$ \\
\hline Study population (N) & 893,360 & 435,417 & 610,538 & 387,539 & 893,360 & 893,360 & 893,360 \\
\hline \multirow[t]{2}{*}{ Children admitted (\%) } & 4.6 & 4.6 & 6.8 & 2.3 & 4.1 & 1.6 & 3.0 \\
\hline & $\mathrm{aHR}(95 \% \mathrm{Cl})$ & aHR $(95 \% \mathrm{Cl})$ & $\mathrm{aHR}(95 \% \mathrm{Cl})$ & aHR $(95 \% \mathrm{Cl})$ & aHR $(95 \% \mathrm{Cl})$ & aHR $(95 \% \mathrm{Cl})$ & aHR $(95 \% \mathrm{Cl})$ \\
\hline \multicolumn{8}{|l|}{ Mode of birth } \\
\hline Vaginal birth - spontaneous onset of labour & 1.00 [Reference] & 1.00 [Reference] & 1.00 [Reference] & 1.00 [Reference] & 1.00 [Reference] & 1.00 [Reference] & 1.00 [Reference] \\
\hline Vaginal birth - labour induction & $1.12(1.09-1.15)$ & $1.12(1.08-1.16)$ & $1.15(1.12-1.18)$ & $1.10(1.04-1.16)$ & $1.13(1.10-1.16)$ & $1.18(1.13-1.23)$ & $1.14(1.10-1.17)$ \\
\hline Caesarean section - pre-labour & $1.19(1.16-1.23)$ & $1.17(1.11-1.22)$ & $1.24(1.20-1.27)$ & $1.20(1.13-1.27)$ & $1.20(1.16-1.23)$ & $1.24(1.18-1.31)$ & $1.22(1.17-1.26)$ \\
\hline Caesarean section - spontaneous onset of labour & $1.20(1.16-1.25)$ & $1.15(1.08-1.22)$ & $1.24(1.20-1.29)$ & $1.22(1.13-1.33)$ & $1.21(1.16-1.26)$ & $1.25(1.17-1.34)$ & $1.24(1.18-1.30)$ \\
\hline Caesarean section - labour induction & $1.23(1.18-1.29)$ & $1.31(1.22-1.41)$ & $1.28(1.22-1.34)$ & $1.18(1.07-1.29)$ & $1.23(1.17-1.29)$ & $1.33(1.23-1.43)$ & $1.26(1.20-1.33)$ \\
\hline \multicolumn{8}{|l|}{ Gestational age (weeks) } \\
\hline $33-36$ & $1.23(1.18-1.29)$ & - & $1.44(1.37-1.50)$ & $1.28(1.16-1.40)$ & $1.23(1.17-1.29)$ & $1.28(1.19-1.38)$ & $1.24(1.17-1.31)$ \\
\hline $37-38$ & $1.15(1.12-1.17)$ & $1.14(1.10-1.19)$ & $1.21(1.18-1.24)$ & $1.17(1.11-1.23)$ & $1.14(1.11-1.17)$ & $1.19(1.15-1.24)$ & $1.15(1.12-1.19)$ \\
\hline $39-42$ & 1.00 [Reference] & 1.00 [Reference] & 1.00 [Reference] & 1.00 [Reference] & 1.00 [Reference] & 1.00 [Reference] & 1.00 [Reference] \\
\hline Formula-only feeding ${ }^{b}$ & $1.18(1.11-1.24)$ & $1.17(1.08-1.26)$ & $1.19(1.14-1.25)$ & $1.20(1.14-1.28)$ & $1.17(1.11-1.24)$ & $1.34(1.25-1.44)$ & $1.24(1.17-1.31)$ \\
\hline
\end{tabular}

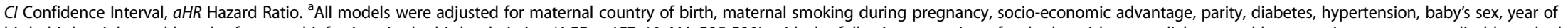
birth, birthweight, and length of stay and infections in the birth admission (AGE or ICD-10-AM: P35-P39), with the following exceptions; for the low-risk group diabetes and hypertension were not applicable and admission to a special care nursery or neonatal intensive care was able be included as preterm was not in the sub-group, for births occurring after 1 July 2007, the indicator for pre/post introduction of universal rotavirus

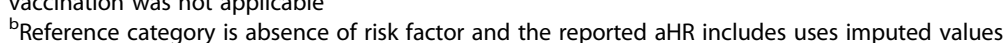

CPopulation restricted to low risk pregnancies: 10th-90th percentile birthweight for gestational age and sex, cephalic presenting, term births ( $\geq 37$ weeks) to mothers aged $20-34$ years without medical conditions dopulation restrist to hils and se

epopulation restricted to children born after the inclusion of rotavirus vaccination in the Australian National Immunisation Program (1 July 2007)

fAge at first hospital admission with a primary diagnosis of AGE was used to define the event

Age at first hospital admission with a primary diagnosis of AGE was used to define the event
${ }^{9}$ The age at first AGE hospital admission within the first year of life was used to define the event. For censored individuals, age was recorded as the earliest of death, first birthday, or end of the study period (30 June 2012)

The age at first AGE hospital admission within the first two years of life was used to define the event. For censored individuals, age was recorded as the earliest of death, second birthday, or end of the study period (30 June 2012) 
The increased rate of AGE admission with decreasing gestational age may be explained in part by the underpreparedness of the newborns immune system, particularly in the gut epithelium, to respond to the initial microbial colonisation at birth. Differences in markers of immune function between infants born before and after 37 weeks gestation have been reported previously [30]. This may explain why vaginal births following labour induction had an increased rate of admission compared to those following the spontaneous onset of labour, as a decision has been made to deliver. Relative to the developmental trajectory of the infant, it may be that the necessary time required for the infant's innate immune response to sufficiently mature has been circumvented.

Variation in gut microbial composition in infants by mode of birth (vaginal birth or caesarean section) and feeding status (breastmilk or formula) is well supported by clinical evidence $[8,31,32]$. These studies highlight that infants delivered by caesarean section or not exposed to breastmilk have less diverse gut microbiota dominated by "bad" bacteria $[8,31,32]$. The similarity of the adjusted associations for caesarean section regardless of the onset of labour is consistent with the theory of beneficial exposure to bacteria at the time of vaginal birth [9, 33]. The higher rate of admission for infants fed only formula is consistent with the idea that with minimal or no breastmilk exposure, there is a loss of the associated microbial and immunological benefits in early childhood. While our estimate (aHR, 1.18) was lower than other studies that have examined breastmilk feeding and AGE, these generally followed infants for the first 6-12 months of life, where a significant proportion of AGE admissions occur [34, 35]. The aHR of 1.34 from our analysis restricted to AGE admissions in the first year of life is similar to these studies, suggesting a potentially stronger association earlier in life.

Previous population-based record-linkage studies of term births and without breastmilk feeding information




found, as we did, an increased risk of AGE for children delivered by caesarean section $[9,10]$. However, with the known association between caesarean section and difficulty initiating breastfeeding [18], the combined association for both factors is of particular interest. We found that despite term birth, children delivered by caesarean section and formula-only feeding at discharge from birth care had a 40-45 \% increased rate of admission. Even for infants with breastmilk exposure, caesarean section was still associated with increased rates of AGE admission (19-23\%). This suggests that for infants delivered by caesarean section, breastfeeding initiation and duration are important factors for reducing the risk of AGE in early childhood and alternative methods of exposure to beneficial bacteria at the time of birth are required.

Changes in clinical obstetric practice have seen an increase in rates of planned birth before 39 weeks gestation and caesarean section worldwide [13-16], and the adverse impact of caesarean section on breastfeeding is well-established [18]. As these trends relate to factors hypothesised to have a common biological basis for affecting the risk of acute gastroenteritis, the impact of a continuation of these patterns on AGE should not be underestimated. Although, the increasing recognition of the potential harms of early elective births and subsequent introduction of clinical guidelines, policies and interventions to reduce labour induction or pre-labour caesarean section for non-medical reasons before 39-40 weeks gestation may counter these trends [36-40].

As planned birth before 39 weeks increases the perceptions of women about what constitutes normal birth is also likely to be altered. Recent studies have demonstrated that almost one in four women believed that a baby was full-term at 34-36 weeks gestation, that one in two believed full term was 37-38 weeks and more than $90 \%$ believed it was safe to deliver before 39 weeks [41, 42]. Another study demonstrated that many women had little knowledge of the benefits or risks of a caesarean section, yet almost half indicated that a caesarean section without medical indication should be given on request [43]. Given the multi-faceted changes in practice and attitudes towards earlier births and interventions, similar studies to ours are vital to assess the impact on long term outcomes to inform clinicians, and women and their families.

The strengths of this study are that it is a large population-based cohort, using data and variables with demonstrated accuracy and validity [44, 45]. Using a large population-based cohort also reduces the impact of genetic diversity and enables complete ascertainment of hospital admissions. The mode and timing of birth and infant feeding at discharge were all statistically significant and consistently so for all analyses (coefficient $p$-values were typically $<0.001)$, so it is unlikely our findings are due to chance. However, some caution is warranted as some of the associations for the study factors are small and by chance a statistically significant association may be found when performing many comparisons. Using available administrative data has some limitations, as not all potentially relevant characteristics such as diet, environment or antibiotic use during pregnancy and early childhood could be investigated. Despite the lack of information on long term breastfeeding outcomes such as the duration of exclusive breastfeeding, previous studies have found in-hospital formula supplementation is associated with early cessation of exclusive or any breastmilk feeding post-discharge [46-48]. Identified cases of acute gastroenteritis were based on hospital admissions only which represent the severe end of the clinical spectrum and do not include mild cases that may be treated through out-patient facilities or primary care services.

\section{Conclusions}

We have shown using a large population-based recordlinkage study that the rate of acute gastroenteritis hospitalisations in early childhood are increased for births by caesarean section or induction of labour, before 39 weeks gestation and for infants fed only formula at discharge from birth care. The combined effects of these factors highlight the benefit of normal birth and early breastmilk exposure, for reducing the risk of gastroenteritis hospitalisation in early childhood. These previously unknown combined effects represent useful information against a backdrop of increasing rates of caesarean section and early planned birth, and their potential impact on gut microbiota and immune system homeostasis.

\section{Availability of data and materials}

The data used in this study cannot be shared by the Authors due to the use and release of the data being subject to data custodian and ethics approval and conditions that require the data only be used for approved research, by approved persons directly involved in the project and following the completion of a confidentiality undertaking prior to the information being released.

\section{Additional files}

Additional file 1: "Imputation.pdf" summarises the imputation approach for formula-only feeding at discharge from birth care, and compares the associations for the study factors and all covariates between the imputation and complete case analysis. (DOC $92 \mathrm{~kb}$ )

Additional file 2: "All adjusted associations.pdf" summarises the adjusted associations for the study factors and all covariates used in the adjustment for the main and additional study populations. (DOC $84 \mathrm{~kb}$ )

Additional file 3: "Additional combined adjusted associations.pdf" summarises the combined associations for the study factors for all additionally investigated study populations. (DOC 443 kb) 


\section{Abbreviations}

AGE: acute gastroenteritis; aHR: adjusted Hazard Ratio; APDC: admitted patient data collection; Cl: confidence interval; ICD-10-AM: International Classification of Disease, 10th revision, Australian Modification; NICU: Neonatal Intensive Care Unit; NSW: New South Wales; PDC: perinatal data collection; SCN: special care nursery.

\section{Competing interests}

The author(s) declare that they have no competing interests.

\section{Authors' contributions}

$J P B$ and NN conceived the project and developed the idea in collaboration with JMS, JRB, JMM and CLR. All authors (JPB, JMS, JRB, JMM, CLR, NN) contributed to the study design, CLR and NN were responsible for data acquisition and JPB analysed the data with the support of JMS. All authors (JPB, JMS, JRB, JMM, CLR, $N N$ ) were involved in the interpretation of results. JPB and NN initially drafted the manuscript and all authors (JPB, JMS, JRB, JMM, CLR, NN) were involved in critical revision of the intellectual content. All authors (JPB, JMS, JRB, JMM, CLR, $\mathrm{NN}$ ) approved the final version of the manuscript.

\section{Acknowledgements}

We would like to acknowledge the NSW Ministry of Health for providing access to population health data and the NSW Centre for Health Record Linkage for linking the data sets. JPB was supported by an Australian Postgraduate Award Scholarship, Sydney University Merit Award and a Northern Clinical School Scholarship Award, CLR was supported by an Australian National Health and Medical Research Council Senior Research Fellowship (\#APP1021025) and NN an Australian National Health and Medical Research Career Development Fellowship (\#APP1067066).

\section{Author details}

${ }^{1}$ Clinical and Population Perinatal Health Research, Kolling Institute, University of Sydney, Sydney, NSW, Australia. ${ }^{2}$ Sydney School of Public Health, University of Sydney, Sydney, NSW, Australia. ${ }^{3}$ Department of Neonatology, Royal North Shore Hospital, Sydney, NSW, Australia. ${ }^{4}$ University Department of Obstetrics, Building 52, Royal North Shore Hospital, St Leonards, NSW 2065, Australia.

\section{Received: 6 February 2015 Accepted: 20 April 2016} Published online: 27 April 2016

\section{References}

1. Parashar UD, Gibson CJ, Bresee JS, Glass RI. Rotavirus and severe childhood diarrhea. Emerg Infect Dis. 2006;12(2):304-6.

2. Dey A, Wang H, Menzies R, Macartney K. Changes in hospitalisations for acute gastroenteritis in Australia after the national rotavirus vaccination program. Med J Aust. 2012;197(8):453-7.

3. Wilking $H$, Hohle M, Velasco E, Suckau M, Eckmanns T. Ecological analysis of social risk factors for Rotavirus infections in Berlin, Germany, 2007-2009. Int J Health Geogr. 2012;11(1):37.

4. Dennehy $\mathrm{PH}$, Cortese MM, Bégué RE, Jaeger JL, Roberts NE, Zhang $\mathrm{R}$, Rhodes P, Gentsch J, Ward R, Bernstein DI, et al. A case-control study to determine risk factors for hospitalization for rotavirus gastroenteritis in U.S. children. Pediatr Infect Dis J. 2006:25(12):1123-31.

5. Burt TD. Fetal regulatory $T$ cells and peripheral immune tolerance in utero: implications for development and disease. Am J Reprod Immunol. 2013; 69(4):346-58.

6. Maynard $\mathrm{CL}$, Elson CO, Hatton RD, Weaver CT. Reciprocal interactions of the intestinal microbiota and immune system. Nature. 2012;489(7415):231-41.

7. Ballard O, Morrow AL. Human milk composition: nutrients and bioactive factors. Pediatr Clin North Am. 2013;60(1):49-74.

8. Azad MB, Konya T, Maughan H, Guttman DS, Field CJ, Chari RS, Sears MR, Becker AB, Scott JA, Kozyrskyj AL. Gut microbiota of healthy Canadian infants: profiles by mode of delivery and infant diet at 4 months. CMAJ. 2013:185(5):385-94.

9. Roberts CL, Algert CS, Ford JB, Nassar N. Mode of delivery may be the risk factor for infant infectious morbidity. Arch Dis Child. 2012:97(8):759.

10. Håkansson S, Källén K. Caesarean section increases the risk of hospital care in childhood for asthma and gastroenteritis. Clin Exp Allergy. 2003; 33(6):757-64.

11. Bager $P$, Simonsen J, Ethelberg S, Frisch M. Cesarean delivery and risk of intestinal bacterial infection. J Infect Dis. 2010;201(6):898-902.
12. Lain SJ, Nassar N, Bowen JR, Roberts CL. Risk factors and costs of hospital admissions in first year of life: a population-based study. J Pediatr. 2013; 163(4):1014-9.

13. Morris JM, Algert CS, Falster MO, Ford JB, Kinnear A, Nicholl MC, Roberts CL. Trends in planned early birth: a population-based study. Am J Obstet Gynecol. 2012:207(3):186.e181-e188.

14. Menacker F, Hamilton BE. Recent trends in cesarean delivery in the United States. NCHS Data Brief. 2010;35:1-8.

15. Betrán AP, Merialdi M, Lauer JA, Bing-Shun W, Thomas J, Van Look $P$, Wagner M. Rates of caesarean section: analysis of global, regional and national estimates. Paediatr Perinat Epidemiol. 2007;21(2):98-113.

16. Nassar N, Schiff M, Roberts CL. Trends in the distribution of gestational age and contribution of planned births in New South Wales, Australia. PLoS ONE. 2013;8(2), e56238.

17. Lutsiv O, Giglia L, Pullenayegum E, Foster G, Vera C, Chapman B, Fusch C, McDonald SD. A population-based cohort study of breastfeeding according to gestational age at term delivery. J Pediatr. 2013;163(5):1283-8.

18. Prior E, Santhakumaran S, Gale C, Philipps LH, Modi N, Hyde MJ. Breastfeeding after cesarean delivery: a systematic review and meta-analysis of world literature. Am J Clin Nutr. 2012;95(5):1113-35.

19. NSW Department of Health. In: Statewide Services Development Branch, editor. Guide to the Role Delineation of Health Services (3rd edition). Sydney: NSW Health Department; 2002.

20. The International Statistical Classification of Diseases and Related Health Problems, Australian Modification - Tabular List of Diseases and Alphabetic Index of Diseases. http://nccc.uow.edu.au/CasemixTools/icd10am/index.html Accessed 6 Nov 2014

21. Bentley JP, Ford JB, Taylor LK, Irvine KA, Roberts CL. Investigating linkage rates among probabilistically linked birth and hospitalization records. BMC Med Res Methodol. 2012;12:149.

22. Newman RD, Grupp-Phelan J, Shay DK, Davis RL. Perinatal risk factors for infant hospitalization with viral gastroenteritis. Pediatrics. 1999;103(1), e3.

23. Australian Bureau of Statistics. Socio-economic Indexes for Areas (SEIFA), Data only, 2006. Catalogue 2033.0.55.001 http://www.abs.gov.au/AUSSTATS/abs@. nsf/DetailsPage/2033.0.55.0012006?OpenDocument Accessed 15 Jul 2014.

24. Chen JS, Roberts CL, Simpson JM, Ford JB. Prevalence of pre-eclampsia, pregnancy hypertension and gestational diabetes in population-based data: impact of different ascertainment methods on outcomes. Aust N Z J Obstet Gynaecol. 2012:52(1):91-5.

25. Tran DT, Roberts CL, Havard A, Jorm LR. Linking birth records to hospital admission records enhances the identification of women who smoke during pregnancy. Aust N Z J Public Health. 2014;38(3):258-64.

26. Dobbins TA, Sullivan EA, Roberts $\mathrm{CL}$, Simpson JM. Australian national birthweight percentiles by sex and gestational age, 1998-2007. Med J Aust. 2012:197(5):291-4

27. Boyle EM, Poulsen G, Field DJ, Kurinczuk JJ, Wolke D, Alfirevic Z, Quigley MA. Effects of gestational age at birth on health outcomes at 3 and 5 years of age: population based cohort study. BMJ. 2012;344, e896

28. Brown HK, Speechley KN, Macnab J, Natale R, Campbell MK. Neonatal morbidity associated with late preterm and early term birth: the roles of gestational age and biological determinants of preterm birth. Int J Epidemiol. 2014;43(3):802-14.

29. Paranjothy S, Dunstan F, Watkins WJ, Hyatt M, Demmler JC, Lyons RA, Fone D. Gestational age, birth weight, and risk of respiratory hospital admission in childhood. Pediatrics. 2013;132(6):e1562-9.

30. Skogstrand K, Hougaard DM, Schendel DE, Bent N-P, Sværke C, Thorsen P. Association of preterm birth with sustained postnatal inflammatory response. Obstet Gynecol. 2008;111(5):1118-28.

31. Biasucci G, Rubini M, Riboni S, Morelli L, Bessi E, Retetangos C. Mode of delivery affects the bacterial community in the newborn gut. Early Hum Dev. 2010;86 Suppl 1:13-5.

32. Penders J, Thijs C, Vink C, Stelma FF, Snijders B, Kummeling I, van den Brandt PA, Stobberingh EE. Factors influencing the composition of the intestinal microbiota in early infancy. Pediatrics. 2006;118(2):511-21.

33. Romero R, Korzeniewski SJ. Are infants born by elective cesarean delivery without labor at risk for developing immune disorders later in life? Am J Obstet Gynecol. 2013;208(4):243-6.

34. Duijts L, Ramadhani MK, Moll HA. Breastfeeding protects against infectious diseases during infancy in industrialized countries. A systematic review. Matern Child Nutr. 2009;5(3):199-210. 
35. Ladomenou F, Moschandreas J, Kafatos A, Tselentis Y, Galanakis E. Protective effect of exclusive breastfeeding against infections during infancy: a prospective study. Arch Dis Child. 2010;95(12):1004-8.

36. Clark SL, Frye DR, Meyers JA, Belfort MA, Dildy GA, Kofford S, Englebright J, Perlin JA. Reduction in elective delivery at $<39$ weeks of gestation: comparative effectiveness of 3 approaches to change and the impact on neonatal intensive care admission and stillbirth. Am J Obstet Gynecol. 2010;203(5):449.e441-6.

37. MacDorman MF, Reddy UM, Silver RM. Trends in stillbirth by gestational age in the United States, 2006-2012. Obstet Gynecol. 2015;126(6):1146-50.

38. Little SE, Zera CA, Clapp MA, Wilkins-Haug L, Robinson JN. A Multi-State Analysis of Early-Term Delivery Trends and the Association With Term Stillbirth. Obstet Gynecol. 2015;126(6):1138-45.

39. March of Dimes. Prematurity Campaign 10-year anniversary report. 2013. Available at:www.marchofdimes.com/materials/prematurity-campaignprogress-report-2012.pdf. Accessed July 6, 2014

40. Chang HH, Larson J, Blencowe H, Spong CY, Howson CP, Cairns-Smith S, Lackritz EM, Lee SK, Mason E, Serazin AC, et al. Preventing preterm births: analysis of trends and potential reductions with interventions in 39 countries with very high human development index. Lancet. 2013; 381(9862):223-34.

41. Goldenberg RL, McClure EM, Bhattacharya A, Groat TD, Stahl PJ. Women's perceptions regarding the safety of births at various gestational ages. Obstet Gynecol. 2009;114(6):1254-8

42. Zhang LY, Todd AL, Khambalia A, Roberts CL. Women's beliefs about the duration of pregnancy and the earliest gestational age to safely give birth. Aust N Z J Obstet Gynaecol. 2015;55(2):156-62.

43. Dursun P, Yanik FB, Zeyneloglu HB, Baser E, Kuscu E, Ayhan A. Why women request cesarean section without medical indication? J Matern Fetal Neonatal Med. 2011;24(9):1133-7.

44. Roberts $\mathrm{CL}$, Bell JC, Ford JB, Morris JM. Monitoring the quality of maternity care: how well are labour and delivery events reported in population health data? Paediatr Perinat Epidemiol. 2009;23(2):144-52.

45. NSW Health Department: Validation Study: NSW Midwives Data Collection 1998. NSW Public Health Bull. 2000;9:97-9

46. Chantry CJ, Dewey KG, Peerson JM, Wagner EA, Nommsen-Rivers LA. Inhospital formula use increases early breastfeeding cessation among first-time mothers intending to exclusively breastfeed. J Pediatr. 2014;164(6):1339-45.

47. Semenic S, Loiselle C, Gottlieb L. Predictors of the duration of exclusive breastfeeding among first-time mothers. Res Nurs Health. 2008;31(5):428-41.

48. Forster D, McLachlan H, Lumley J. Factors associated with breastfeeding at six months postpartum in a group of Australian women. Int Breastfeed J. 2006;1(1):18.

\section{Submit your next manuscript to BioMed Central and we will help you at every step:}

- We accept pre-submission inquiries

- Our selector tool helps you to find the most relevant journal

- We provide round the clock customer support

- Convenient online submission

- Thorough peer review

- Inclusion in PubMed and all major indexing services

- Maximum visibility for your research

Submit your manuscript at wuw biomedcentral.com/submit

) Biomed Central 